\title{
Precision estimation and geomorphological analysis based on the DEM generated by InSAR: Taking Damxung-Yangbajain area as an example
}

\author{
Yaqiong Dai ${ }^{1, *}$ Jinwei Ren $^{1} \quad$ Xuhui Shen ${ }^{1}$ \\ Jingfa Zhang $^{2}$ and Shunying Hong ${ }^{1}$ \\ ${ }^{1}$ Institute of Earthquake Science, China Earthquake Administration, Beijing 100036, China \\ ${ }^{2}$ Institute of Crustal Dynamics, China Earthquake Administration, Beijing 100085, China
}

\begin{abstract}
Digital elevation model (DEM) can be generated by interferometric synthetic aperture radar (InSAR). In this paper, the interferometric processing and analyses are carried out for Damxung-Yangbajain area in Tibet, using a pair of Europe remote-sensing satellite (ERS)-1/2 tandem SAR images acquired on 6 and 7 April 1996. A portion of the InSAR-derived DEM is selected and compared with the 1:50 000 DEM to determine the precision of the InSAR-derived DEM. The comparison indicates that the root mean squared errors (RMSE), which are used to evaluate error, are about 35, 60, 10, and $15 \mathrm{~m}$ in the studied area, mountainous area, basin area and near-fault area, respectively, suggesting that obvious errors are mainly in mountainous area. Besides, the limitation of InSAR technology to generate DEM is analyzed. Our investigation shows that InSAR is an effective tool in geodesy and an important complement to field surveying in some dangerous areas.
\end{abstract}

Key words: InSAR; DEM; geomorphological analysis; Damxung-Yangbajain; root mean squared error CLC number: P315.63 Document code: A

\section{Introduction}

Interferometric synthetic aperture radar (InSAR) becomes a high precise DEM-generating method and a hotspot in earth sciences, because it can provide large scale images with high spatio-temporal resolution day and night (Zebker and Goldstein, 1998; Shan and Ye, 1998). Europe remote-sensing satellite (ERS)-1/2 of European Space Agency (ESA) can provide high coherence SAR data with one day interval for producing DEM. If the InSAR-derived DEM can meet the survey requirements, the relief map can be produced based on the DEM (Liu et al, 2000).

In this paper, a pair of ERS-1/2 tandem data covering Damxung-Yangbajain, Tibet, where the terrain and physiognomy are peculiar, is processed to generate DEM. Furthermore, the relationship between the InSARderived DEM and the specific geological condition, and the comparison between the InSAR-derived DEM and

\section{1:50 000 DEM are studied.}

According to the principle of InSAR (Figure 1), a pair of single look complex (SLC) data can be used to produce interferometric pattern, and then to attain a relative elevation, so $3 \mathrm{D}$ information can be obtained. The detail of formula derivation is omitted here.

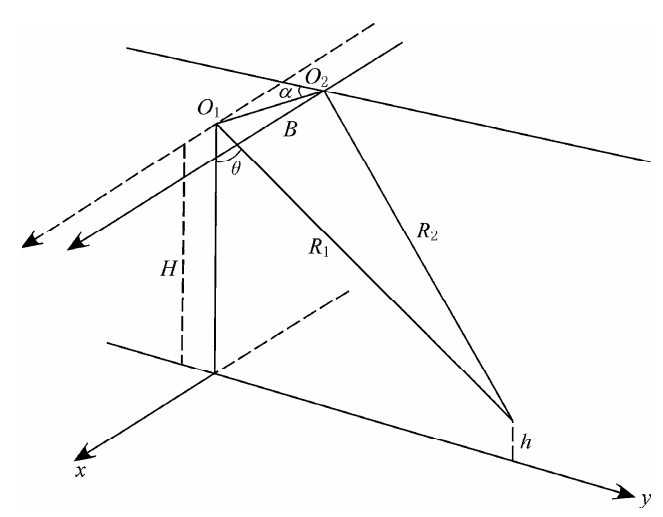

Figure 1 Geometry of SAR interferometry.

\footnotetext{
* Received 16 December 2008; accepted in revised form 13 March 2009; published 10 June 2009.

^Corresponding author. e-mail: daiyaqiong@seis.ac.cn
} 


$$
h=H-\frac{B^{2}-\left(\frac{\lambda \cdot \Delta \varphi}{4 \pi}\right)^{2}}{\frac{\lambda \cdot \Delta \varphi}{2 \pi}-2 B \sin (\alpha-\theta)} \cos \theta
$$

shows the main principle of deriving elevation from the phase difference by InSAR (Wang et al, 2002), where $h$ is the height to be determined, $B$ is the baseline length, $\theta$ is the side looking angle, $\alpha$ is the baseline tilt angle, $\lambda$ is the wavelength, $R_{1}$ and $R_{2}$ are the distance between the scatter and the radar antennas $\left(O_{1}\right.$ and $\left.O_{2}\right)$ respectively, $H$ is the height of the radar, and $\Delta \varphi$ is the difference between the two interferometrical phases.

The main steps of InSAR data processing are shown in Figure 2. The key technology is phase unwrapping and baseline parameter acquiring (Liao and Lin, 2003).

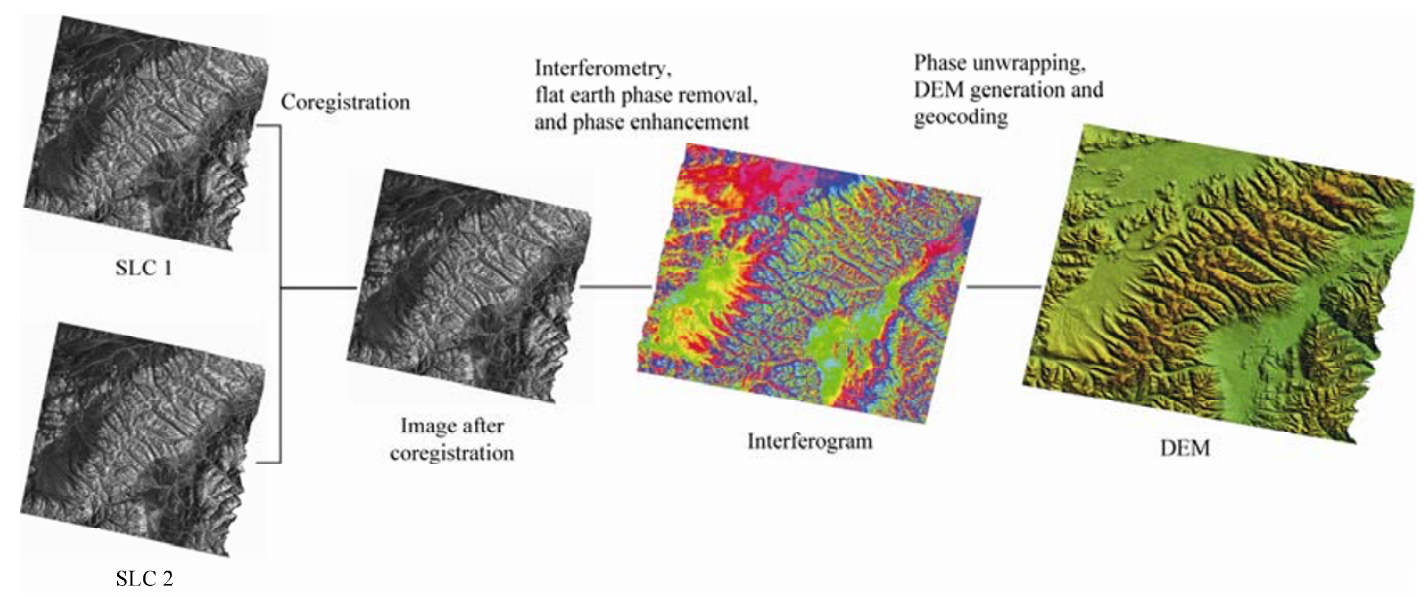

Figure 2 Processes of InSAR.

Extending from northern Samxung in the north to Angong in the south, the Damxung-Yangbajain graben located in the southeast of Nyainqentanglha Mountain consists of six basins (i.e., Gulu, Damxung, Ningzhong, Yangbajain and Jidago) and five transverse uplifts (i.e., Yanta, Juzhila, southern Damxung, southwestern Ningzhong and southern Yangbajain) (Institute of Geology, State Seismological Bureau, 1992). It is a narrow valley of 230-240 km long, 5-25 km wide and 4 300-4500 m high with generally NE-SN trending. The graben is formed in the Himalayan movement (Wang, 1998) and becomes one of the most seismic active areas in Tibet. The 1952 Damxung earthquake and another 1411 earthquake occurred along the Nyainqentanglha southeastern piedmont fault. Figure 3 shows the tectonic environment with faults that distribute in the studied area.

\section{InSAR data and processing}

Compared with other kinds of remote sensing data, SAR data is more economic, reliable and effective. Deformation of faults and elevation information can be obtained by InSAR in the areas, such as Tibet, which are difficult for people to arrive (Zhang and Shao, 1998; Ning et al, 2006). In this paper, we obtain DEM using a

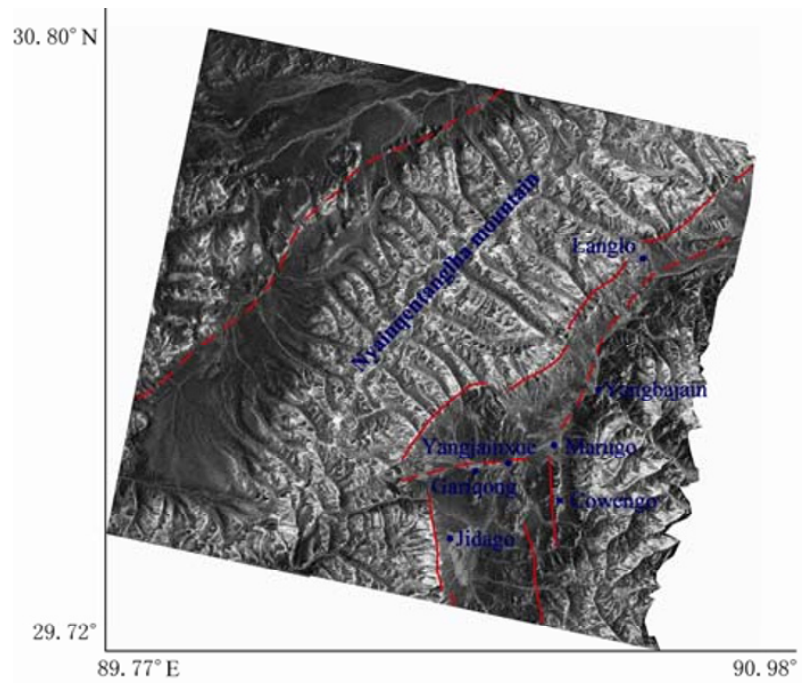

Figure 3 Distribution of active structures and geomorgraphy in the Damxung-Yangbajain graben/half-graben system. The red solid line and dashed line denote strike-slip fault and inferred fault, respectively.

pair of ERS-1/2 tandem data by InSAR technology. The studied area is about $75 \times 67 \mathrm{~km}^{2}$, ranging from $89^{\circ} 55^{\prime} \mathrm{E}$ to $90^{\circ} 40^{\prime} \mathrm{E}$ and from $29^{\circ} 50^{\prime} \mathrm{N}$ to $30^{\circ} 30^{\prime} \mathrm{N}$. The parameters of SAR data are shown in Table 1. 
Table 1 Parameters of ERS-1/2 tandem data

\begin{tabular}{|c|c|c|c|c|c|c|c|c|}
\hline \multirow{2}{*}{ No. } & \multirow{2}{*}{ Satellite } & \multirow{2}{*}{ Orbit } & \multirow{2}{*}{ Track } & \multirow{2}{*}{ Frame } & \multirow{2}{*}{$\begin{array}{l}\text { Date } \\
\text { a-mo-d }\end{array}$} & \multicolumn{3}{|c|}{ Center } \\
\hline & & & & & & Long $/{ }^{\circ} \mathrm{E}$ & & Lat $/{ }^{\circ} \mathrm{N}$ \\
\hline 1 & ERS-1 & 24713 & 176 & 2997 & 1996-04-06 & 90.331 & & 30.261 \\
\hline 2 & ERS-2 & 05040 & 176 & 2997 & 1996-04-07 & 90.334 & & 30.271 \\
\hline \multicolumn{2}{|c|}{ Azimuth resolution $/ \mathrm{m}$} & 28 & \multicolumn{2}{|c|}{ Range resolution $/ \mathrm{m}$} & 26 & Looks & \multicolumn{2}{|l|}{5} \\
\hline \multicolumn{2}{|c|}{ Perpendicular baseline/m } & 95 & \multicolumn{2}{|c|}{ Parallel baseline/m } & 45 & Ambiguity height $/ \mathrm{m}$ & \multicolumn{2}{|l|}{99.04} \\
\hline
\end{tabular}

The interferometric pattern is often affected by three factors: (1) the noise of SAR data; (2) the decorrelation caused by random motion of the Earth's surface, such as vegetation growth, wind influence on vegetation and change of soil humidity; (3) the baseline decorrelation caused by different incident angles ( $\mathrm{Li}$ et al, 2000).

Quality of the interferogram is the most intuitively estimated by coherence image. In this research, the average correlation coefficient is 0.58 . The distribution of correlativities is asymmetric, and high-correlativity points are located in the uneven terrain.

Shuttle radar topography mission (SRTM) with $90 \mathrm{~m}$ resolution is used as the external DEM in data processing. It is subtracted from the interferometric pattern as a known terrain phase, then the residual phase is unwrapped, finally the external DEM is added back to get the elevation. Usage of external DEM can reduce difficulty of phase unwrapping, especially for the precipitous area, so as to guarantee the correctness of the phase unwrapping result. On the other hand, external DEM can provide relative veracious elevation reference for correcting errors if the orbit parameters do not meet requirement. The iterative disk masking algorithm (Atlantis Scientific Inc., 2004) is used in the phase unwrapping.

\section{Precision analysis of DEM}

Scenographs produced by DEM are shown in Figure 4. The SRTM data is available as 3 arc-second (approximately $90 \mathrm{~m}$ resolution) DEM and the planar resolution is about $80.23 \mathrm{~m} \times 92.38 \mathrm{~m}$. The spatial resolution of 1:50 000 DEM is about $24.95 \mathrm{~m} \times 25 \mathrm{~m}$ and that of the InSAR- derived DEM is about $20.68 \mathrm{~m} \times 20.31 \mathrm{~m}$. The scenographs show that SRTM becomes blurry after being zoomed in; whereas the InSAR-derived DEM is better in revealing fine physiognomy compared with SRTM, which can meet the requirements of 1:50 000 map producing.
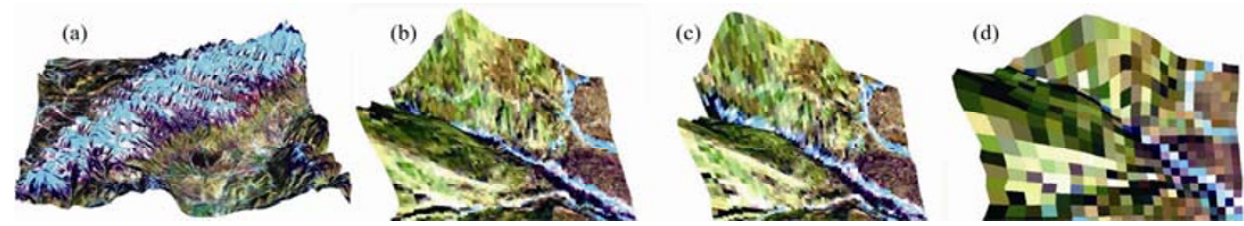

Figure 4 (a) DEM Derived by ERS-1/2 tandem radar image data; (b) InSAR-derived DEM zoomed in; (c) 1:50 000 DEM zoomed in; (d) Shuttle radar topography mission (SRTM) zoomed in.

In order to use DEM appropriately, it is important to analyze whether there is a rule of error distribution or whether the error distribution changes with terrain. Differences between the InSAR-derived DEM and the 1:50 000 DEM are obvious and some blank areas exist in the InSAR-derived DEM because of the specific terrain and radar shadow (Figure 5). Figure 5 also shows the statistical distribution of errors. Errors can be large in the areas with complex hypsography and the precision may not be good if comparing the error statistics with that of the 1:50 000 DEM.

The main reasons for errors are: (1) The measurement error of the secondary planet attitude and orbit can affect the differential interferometry result. High precision

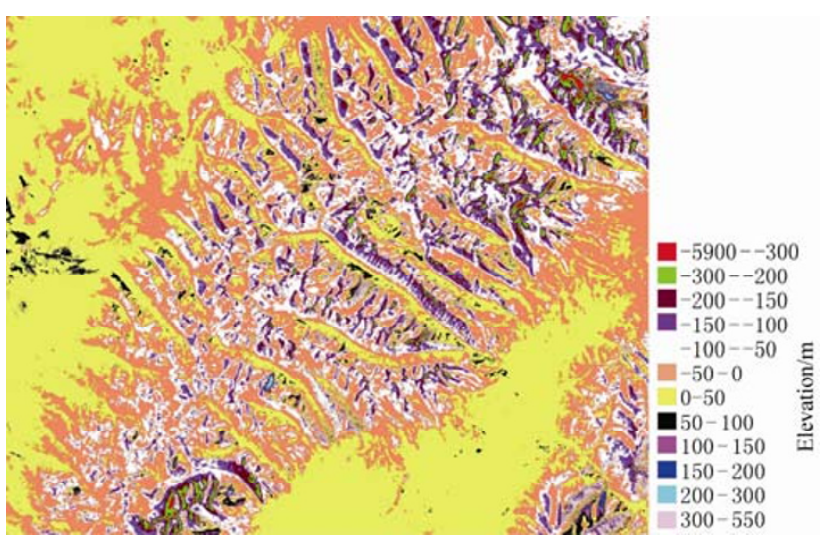

Figure 5 Distribution of the errors between the InSAR-derived DEM and 1:50 000 DEM. 
DEM depends on high precision parameters of orbit and baseline. The error of elevation caused by orbit measurement can be reduced by using high precision orbital parameters or ground control points. (2) The complex hypsography of the studied area can also cause foreshortening and layover in the SAR image. The incident angle of ERS is $23^{\circ}$, so the area with gradient larger than $20^{\circ}$ can not be surveyed. The existence of shadow causes blanks in the image. And the temporal decorrelation caused by vegetation increases the noise, which make phase unwrapping more difficult. (3) The ambiguity height of the data affects the quality of DEM. In this paper, the perpendicular baseline is $95 \mathrm{~m}$, which is a little small. Small perpendicular baseline is good for differential InSAR (D-InSAR), but not good for DEM generating which may be easily affected by error interferer. (4) The spatio-temporal change of atmospheric condition can cause accessional delay of interference phase, which may reduce the precision of DEM. (5) The horizontal resolutions of the two DEMs are different. The InSAR-derived DEM is resampled when compared with 1:50 000 DEM, which may cause errors.

The common methods to estimate precision of DEM include point check, section plane check and contour set check (Tang et al, 1999). The former two ones are used in this paper. Firstly, the InSAR-derived DEM is resampled in order to make resolution the same as 1:50 000 DEM. Then the difference between the InSAR-derived DEM and 1:50 000 DEM is calculated point by point. The largest differences can be several kilometers, which are failing results caused by large gradient or radar shadow. Then 40 points (Table 2) are selected randomly; their longitude, latitude and elevation are acquired and the root mean squared error (RMSE), $r$, is calculated by

Table 2 Comparison between the altitude results of DEMs

\begin{tabular}{|c|c|c|c|c|c|c|}
\hline No. & Lat $/{ }^{\circ} \mathrm{N}$ & Long $/{ }^{\circ} \mathrm{E}$ & InSAR-derived DEM/m & 1:50 $000 \mathrm{DEM} / \mathrm{m}$ & Absolute error /m & Relative error \\
\hline 1 & 30.420366 & 90.033821 & 4854.481934 & 4826.207031 & 28.274902 & $0.585862 \%$ \\
\hline 2 & 30.317602 & 90.183731 & 5112.557617 & 5112.266113 & 0.291504 & $0.005702 \%$ \\
\hline 3 & 30.416153 & 90.235276 & 4913.680176 & 4904.449707 & 9.230469 & $0.188206 \%$ \\
\hline 4 & 30.405528 & 90.360701 & 5220.037109 & 5225.929199 & -5.892090 & $-0.112747 \%$ \\
\hline 5 & 30.177103 & 90.559578 & 4523.543945 & 4517.763672 & 5.780273 & $0.127945 \%$ \\
\hline 6 & 30.225279 & 90.613700 & 4657.555176 & 4655.632324 & 1.922852 & $0.041302 \%$ \\
\hline 7 & 30.242132 & 90.611338 & 4682.810059 & 4678.887207 & 3.922852 & $0.083842 \%$ \\
\hline 8 & 30.160433 & 90.606398 & 4589.191406 & 4590.230469 & -1.039063 & $-0.022640 \%$ \\
\hline 9 & 30.078735 & 90.542397 & 4468.191406 & 4463.591797 & 4.599609 & $0.103047 \%$ \\
\hline 10 & 30.041000 & 90.520276 & 4707.437500 & 4708.329102 & -0.891602 & $-0.018937 \%$ \\
\hline 11 & 30.397285 & 90.368004 & 5413.258301 & 5425.070801 & -11.812500 & $-0.217739 \%$ \\
\hline 12 & 30.208610 & 90.395065 & 4972.975098 & 4972.827637 & 0.147461 & $0.002965 \%$ \\
\hline 13 & 30.338484 & 90.291760 & 5363.283691 & 5350.546387 & 12.737304 & $0.238056 \%$ \\
\hline 14 & 30.265212 & 90.377883 & 5959.395020 & 5959.956543 & -0.561523 & $-0.009422 \%$ \\
\hline 15 & 30.082765 & 90.235276 & 5231.559570 & 5211.685059 & 19.874511 & $0.381345 \%$ \\
\hline 16 & 30.147794 & 90.141851 & 5452.041504 & 5476.702148 & -24.660644 & $-0.450283 \%$ \\
\hline 17 & 30.254771 & 90.107488 & 5200.050293 & 5199.638184 & 0.412109 & $0.007926 \%$ \\
\hline 18 & 30.384646 & 90.471093 & 5611.527832 & 5638.745605 & -27.217773 & $-0.482692 \%$ \\
\hline 19 & 30.326028 & 90.490852 & 5567.168457 & 5560.940918 & 6.227539 & $0.111987 \%$ \\
\hline 20 & 30.353139 & 90.616063 & 5590.375000 & 5600.552734 & -10.177734 & $-0.181727 \%$ \\
\hline 21 & 30.321815 & 90.591579 & 5268.854980 & 5220.986328 & 47.868652 & $0.916851 \%$ \\
\hline 22 & 30.304962 & 90.552276 & 5109.443359 & 5115.711426 & -6.268067 & $-0.122526 \%$ \\
\hline 23 & 30.089176 & 90.195973 & 5899.357910 & 5931.280762 & -31.922852 & $-0.538212 \%$ \\
\hline 24 & 30.399300 & 90.129609 & 5075.857910 & 5083.979980 & -8.122070 & $-0.159758 \%$ \\
\hline 25 & 30.059868 & 90.055943 & 5533.756836 & 5525.579590 & 8.177246 & $0.147989 \%$ \\
\hline 26 & 30.273639 & 90.380245 & 6128.249023 & 6164.446777 & -36.197754 & $-0.587202 \%$ \\
\hline 27 & 30.302947 & 90.311519 & 6114.982910 & 6059.259766 & 55.723144 & $0.919636 \%$ \\
\hline 28 & 30.395087 & 90.554639 & 6071.896973 & 6077.871582 & -5.974609 & $-0.098301 \%$ \\
\hline 29 & 30.328043 & 90.490852 & 5446.993652 & 5447.192871 & -0.199219 & $-0.003657 \%$ \\
\hline 30 & 30.281882 & 90.372943 & 6089.278320 & 5995.455566 & 93.822754 & $1.564898 \%$ \\
\hline 31 & 30.237919 & 90.559578 & 5174.058105 & 5190.277832 & -16.219727 & $-0.312502 \%$ \\
\hline 32 & 30.265212 & 90.210792 & 5437.871582 & 5553.077148 & -115.205566 & $-2.074626 \%$ \\
\hline 33 & 30.242132 & 90.063245 & 5026.275879 & 4972.091309 & -4.184570 & $1.089774 \%$ \\
\hline 34 & 30.403513 & 90.444247 & 5705.863770 & 5758.571777 & -52.708007 & $-0.915297 \%$ \\
\hline 35 & 30.372006 & 90.400004 & 5285.053711 & 5323.619629 & -38.565918 & $-0.724430 \%$ \\
\hline 36 & 30.095405 & 90.446609 & 4708.444824 & 4665.668945 & 42.775879 & $0.916822 \%$ \\
\hline 37 & 30.112257 & 90.586639 & 4917.083984 & 4968.346191 & -51.262207 & $-1.031776 \%$ \\
\hline 38 & 30.204397 & 90.601459 & 4590.818848 & 4592.651855 & -1.833007 & $-0.039912 \%$ \\
\hline 39 & 30.175088 & 90.616063 & 4690.658203 & 4691.560059 & -0.901856 & $-0.019223 \%$ \\
\hline 40 & 30.223264 & 90.557216 & 5043.203613 & 5045.349609 & -2.145996 & $-0.042534 \%$ \\
\hline
\end{tabular}


the following equation:

$$
r=\sqrt{\frac{\sum_{i=1}^{n}\left(y_{1}-\hat{y}_{1}\right)^{2}}{n}},
$$

where $y_{1}$ and $\hat{y}_{1}$ are mensurated result and forecasted result respectively, and $n$ is the number of the samples.

RMSEs of the whole image and 40 points are separately $53.21 \mathrm{~m}$ and $33.59 \mathrm{~m}$ with largest error of $115.21 \mathrm{~m}$. There are 10 points with errors above $35 \mathrm{~m}$. The difference in RMSE between 40 points and that of the whole image is less than 1 pixel.
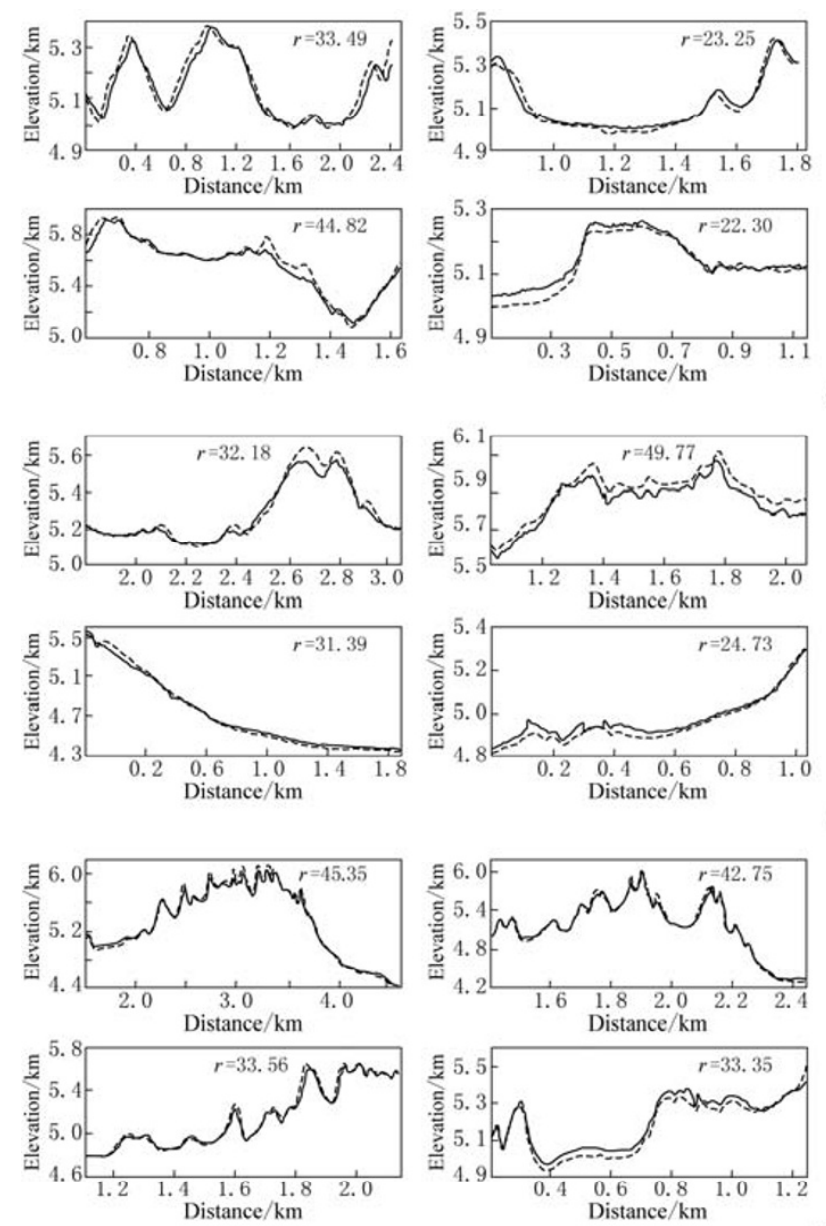

ERS-1/2 DEM
Section planes are made randomly on DEM in order to validate the result. Eight section plane curves are made in $x$-, $y$-, and arbitrary direction respectively (Figure 6). As listed in Table 3, RMSE of each section plane shows the difference between the RMSEs is less than 1 pixel. Besides, the InSAR-derived DEM exhibits the same trend of terrain and main hypsographic features as that of 1:50 000 DEM with average correlation coefficient of 0.99 .

RMSE of section planes in different directions is basically consistent to that of 40 points and the whole image with the difference of less than 1 pixel. So it can
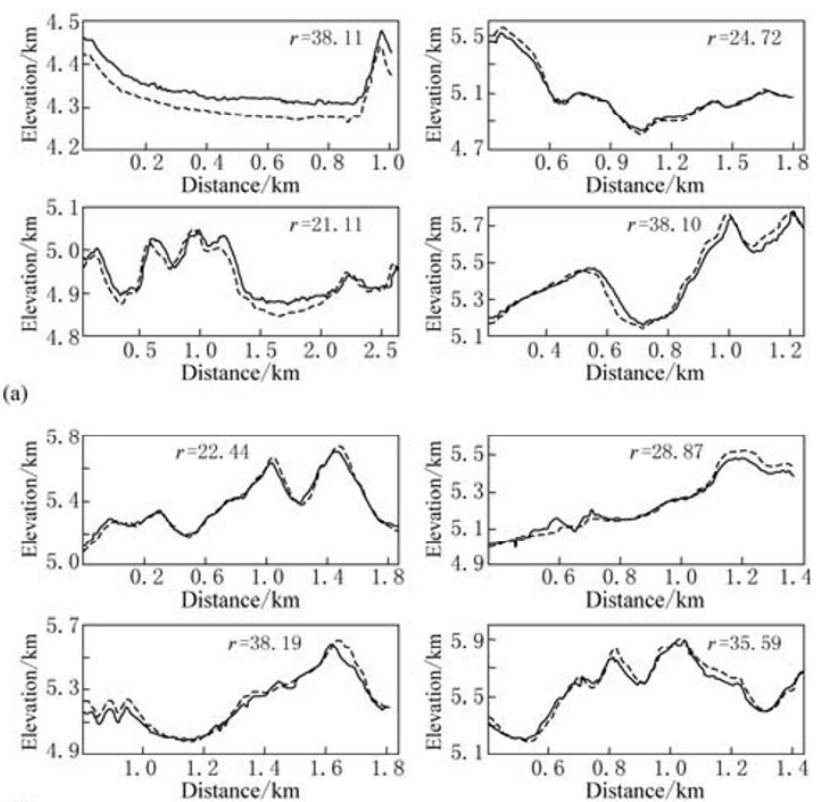

(b)
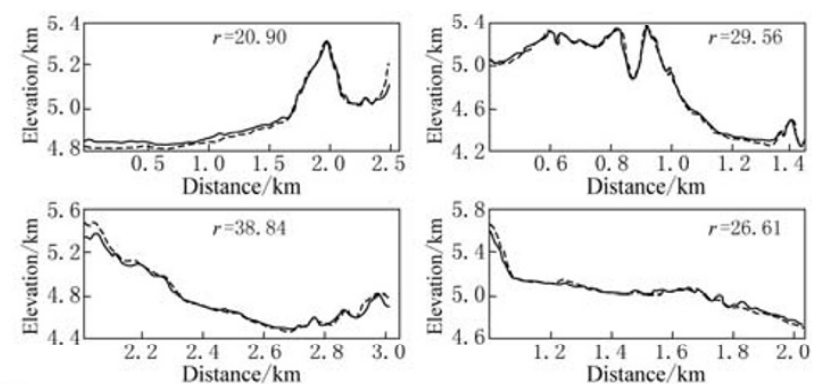

1:50000 DEM

Figure 6 Comparative relief profiles between the identical points of InSAR-derived DEM and 1:50 000 DEM in $x$ - (a), $y$ - (b) and arbitrary directions (c).

Table 3 RMSE of different profiles in $x-, y$-, and arbitrary directions

(unit in $\mathrm{m}$ )

\begin{tabular}{|c|c|c|c|c|c|c|c|c|c|}
\hline Direction & $r_{1}$ & $r_{2}$ & $r_{3}$ & $r_{4}$ & $r_{5}$ & $r_{6}$ & $r_{7}$ & $r_{8}$ & Average \\
\hline$x$ direction & 33.49 & 23.25 & 38.11 & 24.72 & 44.82 & 22.30 & 21.11 & 38.10 & 30.74 \\
\hline$y$ direction & 32.18 & 49.77 & 22.44 & 28.87 & 31.39 & 24.73 & 38.19 & 35.59 & 32.89 \\
\hline Arbitrary direction & 45.35 & 42.75 & 20.90 & 29.56 & 33.56 & 33.35 & 38.84 & 26.61 & 33.86 \\
\hline
\end{tabular}

Note: $r_{1}, r_{2}, \cdots, r_{8}$ denote the root mean squared error of the eight sections. 
be considered that the precision of InSAR-derived DEM of the Damxung-Yangbajain area is about $35 \mathrm{~m}$. By the same estimating method, we get the precision is about 60,10 and $15 \mathrm{~m}$ in mountainous area, basin area and the near fault area, respectively.

\section{Geomorphological analysis}

The Nyainqentanglha southeastern piedmont fault, i.e., western boundary fault of Damxung-Yangbajain graben/half-graben system, strikes northeast and dips southeast, with total length of $240 \mathrm{~km}$. The fault exhibits complex geometric pattern and active characteristic. The fault is divided into three sections, i.e., northern section with NNE-trend, central section and southern section. Among them, the central section striking $\mathrm{N} 40^{\circ}-50^{\circ} \mathrm{E}$ and with length of $130 \mathrm{~km}$, consists of several strands characterized by left-lateral strike-slip normal fault, forming three subzones with left-step en echelon pattern. The stepovers generate pull-apart structures in northwest of Damxung and north of Yangbajain, where develop two subparallel $\mathrm{N} 30^{\circ}-40^{\circ}$ E-trending faults and shear-extensional fracture, respectively (Institute of Geology, State Seismological Bureau, 1992).

The NE-trending Damxung-Yangbajain graben and half-graben system consists of six sub-basins and five horsts in turn. The western boundary of the system is controlled by the active Nyainqentangla southeastern piedmont fault, and the eastern boundary is controlled partly by active faults (Figure 7). The system is asymmetric in the cross-section due to different activities

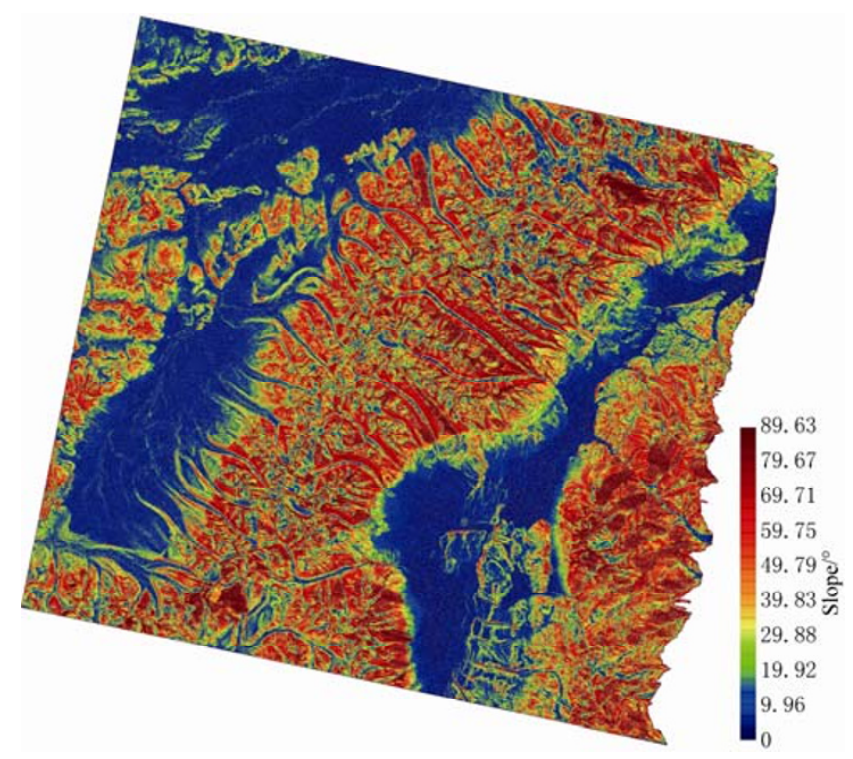

Figure 7 Slope map produced by InSAR-derived DEM. along both eastern and western boundaries of the system.

The central and southern section of the Nyainqentanglha southeastern piedmont fault starts at north of Damxung, extends toward southwest to west of Yangbajain, then turns southward to west of Yangyinxiang with a total length of $136 \mathrm{~km}$. The surface rupture of the central-southern section is divided into two sections by strike and active characteristics. One is left-lateral strike-slip normal fault, extending from Damxung in the north to Yangbajain in the west along the strike of $\mathrm{N} 45^{\circ} \mathrm{E}$, with length of $108 \mathrm{~km}$. The maximum vertical offset is 8-9 $\mathrm{m}$ near the west of Ningzhong and the maximum horizontal offset 11-13 m near the north of Yangbajain. The other extends from the Yangbajain to Yangyinxiang along north-south direction, with a length of $28 \mathrm{~km}$. It consists of a series of tensile and shear-tensile ruptures with right-lateral offset $2-4 \mathrm{~m}$ and vertical offset 1-4 m. The maximum vertical offset is $5 \mathrm{~m}$ (Institute of Geology, State Seismological Bureau, 1992). The central and southern section of the fault is associated with the south of Damxung M8 earthquake in the year 1411. Field investigation in the studied area also demonstrates that the surface rupture is still obvious (Figure 8).

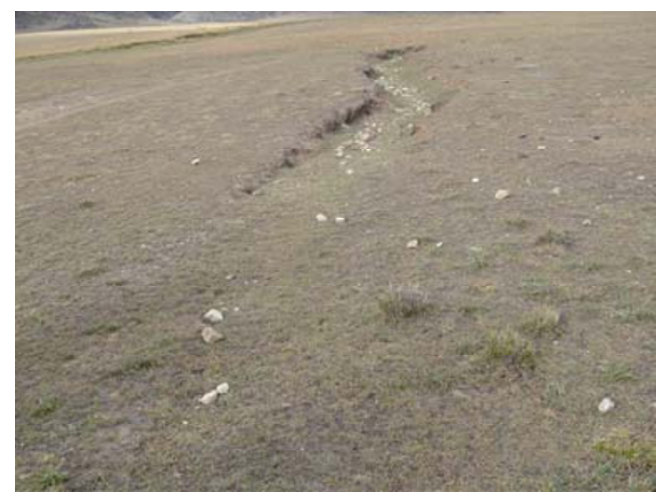

Figure 8 Surface rupture caused by Damxung earthquakes in history.

\section{Conclusions}

Based on a pair of ERS-1/2 data on 6 and 7 April 1996, this paper generates the elementary DEM of Damxung-Yangbajain area, from which we can get abundant hypsographic information, by InSAR technology. Comparing with SRTM (90 m resolution) and 1:50 000 DEM (25 $\mathrm{m}$ resolution), the resolution of InSAR-derived DEM is about $20 \mathrm{~m}$, which suggests that DEM generated by InSAR can meet the 1:50 000 mapping requirement in terms of resolution. Then we esti- 
mate the precision by comparing it with 1:50 000 DEM, by taking RMSE as the error index. The result indicates that errors exist to different extents, while obvious errors are mainly in mountainous area. And the error in the whole studied area, mountainous area, basin area and the near-fault area are about 35, 60, 10 and $15 \mathrm{~m}$, respectively.

By the experimental study of the DamxungYangbajain area, the conclusion can be drawn that InSAR is a very effective surveying method specially in the areas which are difficult for people to reach, and DEM can be generated by InSAR more automatically compared with other surveying methods.

The main steps of data processing include the coregistration, resampling of the SAR image pair, calculation of the phase interferometric pattern, phase unwrapping, calculation of baseline, geometry transformation and geocoding. Among them, phase unwrapping and calculation of parameters and models of the baseline are need to be further studied.

The ways to improve the precision of interferential DEM include: (1) increasing the temporal correlation which relies on the design of hardware system; (2) controlling the baseline decorrelation and decreasing the ambiguity height which depends on the selection of interferential pair eclectically, i.e., the baseline should not be too large or too small, and $200-300 \mathrm{~m}$ is appropriate for ERS-1/2 system (Zeng and Jiao, 1998); (3) the models and parameters should be calculated precisely; (4) methods of correcting atmospheric phase delay should be improved.

The technology of InSAR including arithmetic, software, analysis method and hardware can meet the requirements of practical application. However, accuracy of the data should be improved. The data in use is acquired from the same secondary planet imaging in two adjacent orbits, and it is effected by excursion, aviation change and earth motion in certain period, which can cause errors. The precision of InSAR can be highly improved along with the launch of bi-antenna radar system.

Acknowledgments This paper is supported by the Basic Scientific Research Special Fund from Institute of Earthquake Science, China Earthquake Administration (02092403 and 0207690224).

\section{References}

Atlantis Scientific Inc. (2004). EV-InSAR User's Guide. Version 3.1. Atlantis Scientific Inc., Nepean, Ontario, Canada, 39-40.

Institute of Geology, State Seismological Bureau (1992). Active Faults in the Central Tibet. Seismological Press, Beijing, 93-96 (in Chinese with English abstract).

Li D R, Zhou Y Q and Ma H C (2000). Principle and applications of interferometric SAR. Survey Science 25(1): 9-12 (in Chinese).

Liao M S and Lin H (2003). Interferometric SAR-Principle and Data Processing. Surveying and Mapping Press, Beijing, 38-41 (in Chinese).

Liu G X, Ding X L and Liu Y Q (2000). New and potential technology for observation of earth from space: Synthetic aperture radar interferometry. Advance in Earth Sciences 15(6): 734-740 (in Chinese with English abstract).

Ning S Z, Ren J W, Shan X J, Tao W and Zhou M D (2006). Application of spaceborne synthetic aperture radar interferometry on morphotectonic research in Bengcuo area of Tibet. Seismology and Geology 28(1): 111-118 (in Chinese with English abstract).

Shan X J and Ye H (1998). The InSAR technique: Its principle and applications to mapping the deformation filed of earthquakes. Acta Seismologica Sinica 11(6): 759-769.

Tang X M, Lin Z J and Wu L (1999). Estimation of DEM precision based on counters and elevation point. Remote Sensing Information 55(3): 7-10 (in Chinese).

Wang C, Zhang H and Liu Z (2002). Secondary Planet Interferometric Synthetic Aperture Radar. Science Press, Beijing, 46-50 (in Chinese).

Wang Y P (1998). Principal features of the active tectonics in Qinghai-Xizang Plateau. In: Institute of Geology, China Seismological Bureau eds. Study on Tectonic Faults (6). Seismological Press, Beijing, 22-26 (in Chinese).

Zebker H A and Goldstein R M (1998). Topographic mapping from interferometric SAR observations. J Geophys Res 91(9): 4 993-4 999.

Zeng Q M and Jiao J (1998). Principles and Applications of SAR. 4th ed. Remote Sensing Information 4: 42-46 (in Chinese).

Zhang J F and Shao Y (1998). InSAR and its applications. Seismology and Geology 20(3): 277-287 (in Chinese). 